TITLE:

\title{
Mechanism of Permafrost Landslide Based on GPS and Resistivity Surveying
}

\section{$\operatorname{AUTHOR}(\mathrm{S})$ :}

Shan, Wei; Hu, Zhaoguang; Jiang, Hua; Guo, Ying; Wang, Chunjiao

\section{CITATION:}

Shan, Wei ...[et al]. Mechanism of Permafrost Landslide Based on GPS and Resistivity Surveying. Matsue Conference Proceedings (The Tenth International Symposium on Mitigation of Geo-disasters in Asia 2012: 82-94: 共同研究（一般研 究集会) 24K-02

ISSUE DATE:

2012-10-08

URL:

http://hdl.handle.net/2433/180411

RIGHT: 


\title{
Mechanism of Permafrost Landslide Based on GPS and Resistivity Surveying
}

\author{
Wei Shan, Zhaoguang Hu, Hua Jiang, Ying Guo and Chunjiao Wang
}

\begin{abstract}
The formation and development of landslide at K178 +530 section of Bei'an-Heihe expressway was mainly affected by armchair shape topography of the slope, hydrologic and climatic conditions, frost-heave cycles, and geotechnical engineering activities for highway construction. The study employed data obtained from portable global positioning system (GPS) equipment and high-resolution resistivity profiling to characterize landslide mass dynamic characteristics, stratigraphic log profile of the landslide and analyze the motion mechanism of the landslide in K178 +530 section of Bei'an-Heihe expressway. Lithologic and geological information were obtained from four monitoring wells drilled along the slope. About 40 GPS gauge piles were placed at different positions on the sliding mass on September 13, 2010, to accurately determine the time, direction and rate of movement at different locations and analyze the role of freezing, thawing and rainfall on the sliding mass. The field monitoring campaign lasted for more than 1 year. Between June, and September 2010, we carried out a high-resolution resistivity investigation to obtain resistivity profile logs of the slope. The results show that the landslide material resistivity profile logs show a significant difference before and after the sliding. Result shows that before the movement of the slope, data obtained from resistivity log shows a uniform signature, while after or during sliding, the resistivity signature changed. The change was due to the development of a slip surface within the landslide mass.
\end{abstract}

Keywords Landslide $\cdot$ Permafrost region $\cdot$ GPS $\cdot$ High-density resistivity method

W. Shan $(\bowtie) \cdot$ Z. Hu $\cdot$ H. Jiang $\cdot$ Y. Guo $\cdot$ C. Wang Northeast Forestry University, 150040 Harbin, China e-mail: shanwei456@163.com 


\section{Foreword}

Landslide is a downward movement of soil, rock or a mixture of both along slopes under the effect of gravity (Kong et al. 2008; GB50021-2001 2002). It is one of the main disasters associated with mountainous regions where near vertical slopes lie close to highways and poses serious threats to lives and properties (Feng et al. 1999; Shan et al. 2008; Liu et al. 2007).

Accurate determination of the sliding surface of a landslide mass and failure characteristics is an important factor in slope stability analysis and landslide prevention programs (He 1991). The purpose of landslide geotechnical engineering investigation is to determine these important parameters which play vital roles in disaster prevention and mitigation (Zhu et al. 2008).

This article utilizes results from GPS technology and high-resolution resistivity profiling to study motion mechanism and failure style of landslides in permafrost regions. The study area is located in Lesser Khingan Range central region at K178 + 530 section of Bei'an-Heihe Expressway, in high altitude permafrost degraded region of China. We used GPS technology to monitor the morphological changes of the landslide and employed high-resolution resistivity profiling to obtain stratigraphic log profile of the landslide which aided in determining the failure surface and other changes in discontinuity of horizontal strata.

\section{General Situation of Study Area}

\subsection{Physical Geography of Study Area}

The study area is located in Lesser Khingan Range central region, in high altitude permafrost degraded belt of China. Climatic data of the area shows that spring season is warm and short; summer hot and rainy with cool and short autumn period and cold long winter season. Annual average temperature of the region is $-0.8{ }^{\circ} \mathrm{C}$, annual average precipitation is $510-572 \mathrm{~mm}$, with high rainfall intensity between July and September, which accounts for $60 \%$ of annual total precipitation. Winter starts in October and ends in late March or early April. Permafrost deposits dominates the upper part of the slope with maximum seasonal frozen depth is $2.30-2.50 \mathrm{~m}$ The geomorphology of the area is mainly low mountains and hills with high topographic relief in high altitude permafrost region (Fig. 1). 


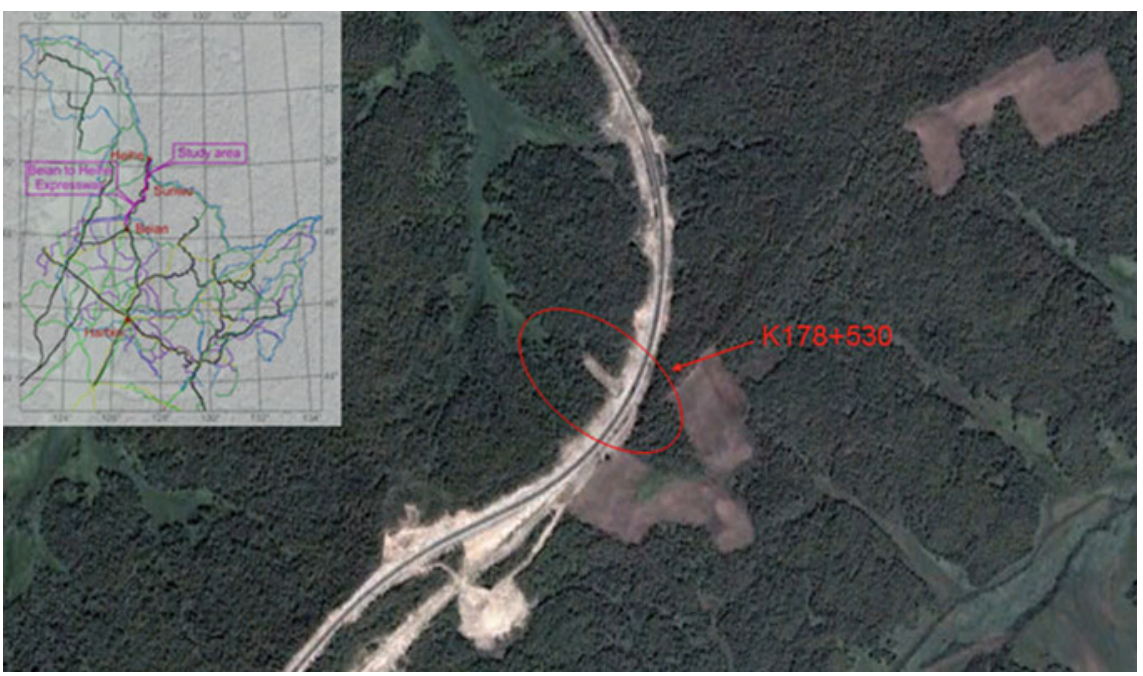

Fig. 1 K178 + 530 geographical position

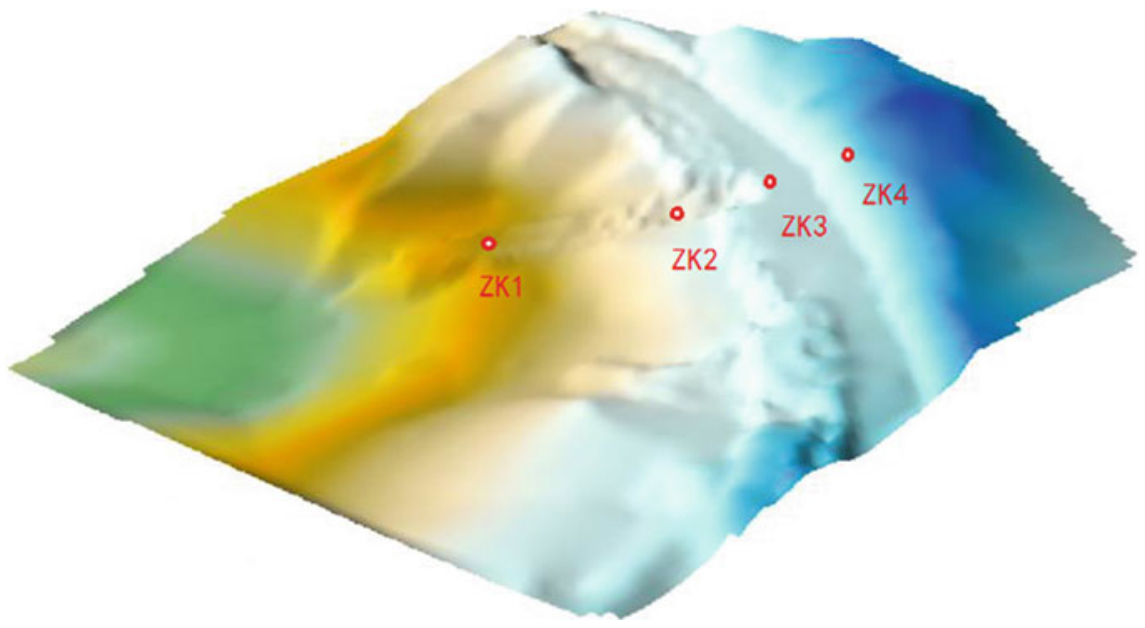

Fig. 2 K178 + 530 drilling holes arrangement

\subsection{Geological Structure of Study Area}

In order to obtain lithologic and geological characteristics of the landslide section, we drilled four monitoring holes to depths of 14-26 m. Figure 2 shows the arrangement of the monitoring holes. 
The stratigraphic log profile of the landslide material is made up of Cretaceous mudstone and sandstone, Tertiary pebbly sandstone, and Quaternary loose sediments. These are further subdivided into the following units:

(1) Subgrade soil or highway construction material: This unit includes subgrade materials, Tertiary pebbly sandstone, Cretaceous mudstone and sandy mudstone with characteristic reddish-brown colouration. It is wet, loose when dry and plastic once saturated. Thickness is about $1-1.5 \mathrm{~m}$ at the upper and middle section of log profile.

(2) Silty clay: This layer shows intercalation of silts and clay which enhanced pore water infiltration. It is soft and usually wet, poorly graded, brownish appearance with visible seepage outlets. This unit lies between $1.5-3.8 \mathrm{~m}$ on the upper section of the log profile (ZK2 hole), and in depth of $0-6.7 \mathrm{~m}$ in the middle and lower sections of the slope (ZK1 hole). Intercalation of fine sand and shale were also observed, with thicknesses which range from $1 \mathrm{~cm}$ to $10 \mathrm{~cm}$. Water permeability is also high at the sand-shale contacts.

(3) Tertiary pebbly sandstone: This unit is located in depth range of $3.8-4.5 \mathrm{~m}$, on the upper section of the landslide (ZK1 hole). It is weathered, loose, poorly graded composed pebbles distributed in a fine sand matrix which enhanced surface water infiltration.

(4.1) Weathered siltstone: This unit occupies depth range of 4.5-14.3 $\mathrm{m}$ on the upper section of the landslide (ZK1 hole). It shows thin parallel lamination, Sandy structure, bedding construction and week bonding force, all the mineral constituents is weathered into secondary minerals, the locality has clay substance, and the structure has been compromised, the ability of water permeability is vey bad.

(4.2) Weathered mudstone: This unit is located below the silty clay layer at depth range of $6.7-8.0 \mathrm{~m}$ for ZK1 hole and below siltstone layer at depth of $14.3 \mathrm{~m}$ in ZK2. The rocks are unconsolidated, soft, and relatively impermeable. Colour of weathered sample is gray while fresh sample colour is black.

(5) Completely weathered mudstone: This unit dominates the basal section of the slope which is distributed around ZK1 and ZK2. It shows a massive structure lacking bedding planes with very fine grain sizes and characteristic black-gray appearance for fresh sample and gray for weathered sample (Fig. 3).

\section{Formation Mechanism and Morphological Characteristics of Landslide}

The formation and development of the landslide at $\mathrm{K} 178+530$ section of Bei'an-Heihe expressway mainly was affected by the topography, engineering geology, hydrology and climate characteristics, armchair shape topography, active groundwater change, intense freeze-thaw cycle and civil engineering activities. Because of the highway construction, landslide materials dislodged from the unstable slope make up one-third part of exposed soil in the area; perennial fissure 


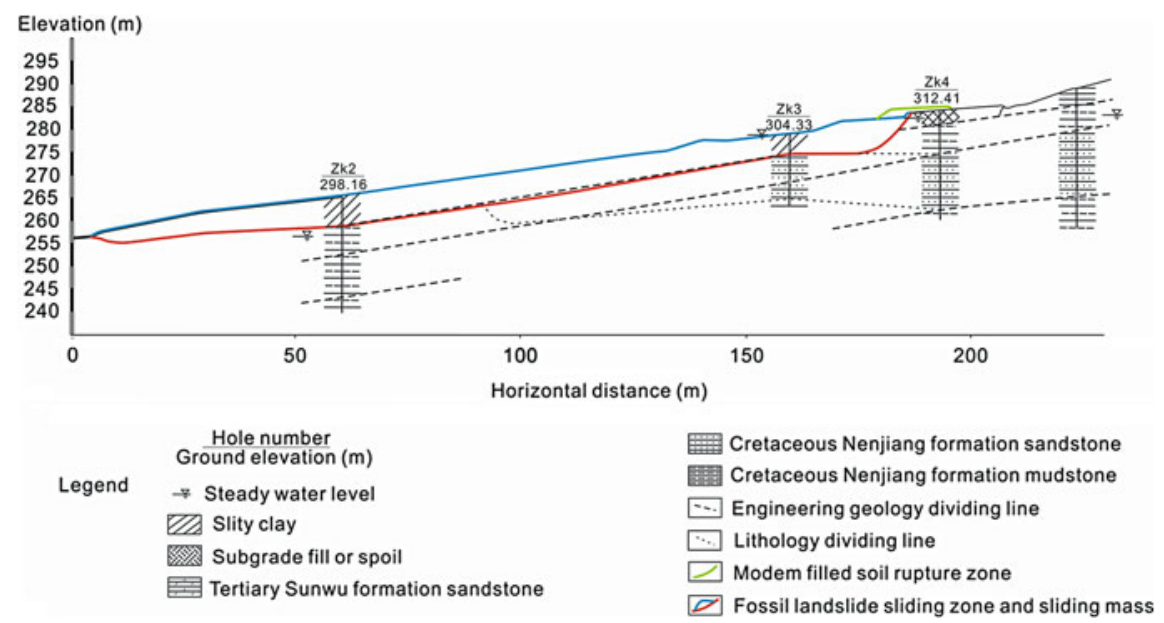

Fig. 3 Geological structure of $\mathrm{K} 178+530$

spring water flows from the main scarp (left side of the road) of the landslide, eroding the landslide body; high precipitation in rainy seasons and surface water infiltration into the slope increases the shear stress within the slope. Infiltration of snowmelt water, fissure water and rainwater provided water source for landslide liquefaction. High permeable slope material provided channel way for water infiltration while mudstone and sandstone units with low permeability form aquiclude. Rupture surfaces observed within gravelly sand and silty clay above the aquiclude was influenced by infiltration water to reach saturation, forming rupture surface. In late July 2010, the slope started to slide.

Slip surface of the upper part of the slope is located at depth range of $4.5 \mathrm{~m}$, the slip surface is at the interface of gravel sand and siltstone; rock unit underlying the slip surface is poorly consolidated siltstone. Slip surface of the middle and lower parts of the slope is in the depth range of $6.5 \mathrm{~m}$, which is the interface of silty clay and mudstone. The rock unit underlying the slip surface is moderately consolidated mudstone.

This landslide belongs to Chair-bedding push type landslide of superficial area, located at the left side of the embankment road. Soil leftover from the road construction and subgrade filling soil slide along the gully, The $178+530$ landslide presents a tongue shape, with width of about $20-30 \mathrm{~m}$, acreage of about $5000 \mathrm{~m}^{2}$; the distance from toe to rear edge is about $200 \mathrm{~m}$. Vertical elevation of the toe section is $254 \mathrm{~m}$ while elevation of rear edge is $285 \mathrm{~m}$. Leading edge of the landslide pushes up humus soil of original ground surface to slide forward. And arcuate dislocation in the rear edge, the dislocation was in rang of widen subgrade. There are downtrees at leading edge of the landslide. 


\section{Landslide Monitoring Based on GPS}

\subsection{The Arrangement of GPS Monitoring Piles}

On 22 of July, 2010, two deformation monitoring pipes on the landslide body were sheared to the depth of $4.2 \mathrm{~m}$ and $6.5 \mathrm{~m}$ respectively under the ground; the sensor connection lines were also sheared. The result was used in monitoring the motion mechanism of the landslide. We arranged 49 GPS gauge piles at different positions on the landslide on 13 of September, 2010. Using GPS to monitor the moving data of these gauge piles, monitoring cycle is more than 1 year.

The arrangement of GPS gauge piles is shown in Fig. 4. From the rear edge of landslide to the leading edge we respectively arranged 11 rows in order, respectively arranging on the both sides of the outside landslide, the central location on the top of landslide and close to the rear edge of landslide. The distance from the first row to the rear edge of landslide is $15 \mathrm{~m}$, and the numbers from left to right 1\#-3\#; The distance from the second row to the rear edge of landslide is $30 \mathrm{~m}$, and the numbers from left to right 4\#-10\#; The distance from the third row to the rear edge of landslide is $50 \mathrm{~m}$. The distance from the forth row to the rear edge of landslide is $70 \mathrm{~m}$. The distance from the fifth row to the rear edge of landslide is $93 \mathrm{~m}$. The distance from the sixth row to the rear edge of landslide is $119 \mathrm{~m}$. The distance from the seventh row to the rear edge of landslide is $134 \mathrm{~m}$. And the others are distribution near the leading edge of the landslide. These GPS monitoring piles can monitor the sliding condition at the upstream and middle stream, as well as the downstream of the landslide. It also can monitor the centre, near the edges and outside locations etc. of the landslide. The monitoring cycle lasted for more than one year.

\subsection{Gauge Piles Motion Characteristic at Different Positions}

By the first row of gauge piles sliding displacement graph (as shown in Fig. 5), From September 13, 2010 to November 2010, 1\#, 2\# and 3\# gauge piles of sliding displacement were $6.90 \mathrm{~m}, 8.05 \mathrm{~m}$ and $4.12 \mathrm{~m}$ respectively. From November 2010 to mid-late May 2011, landslide was not sliding. Until early June 2011, landslide began to slide, and by September 25, 2011, sliding displacements of 1\#, 2\# and 3\# gauge piles were $45.70 \mathrm{~m}, 65.01 \mathrm{~m}$ and $23.82 \mathrm{~m}$ in 1 year. In the same crosssectional inside, slip rate in a central location close to slip rate near the edge.

Figure 6 shows the displacement graph of the second row gauge piles. From the front row and second row sliding displacement graph of gauge piles, from monitoring commencement day (September 13, 2010) to the middle of November, Landslide had been in sliding state. After mid-November, land surface began to freeze, and until the end of May 2011, landslide had been always in steady state. From early June 2011, Landslide began to slide once again. During the same time, 


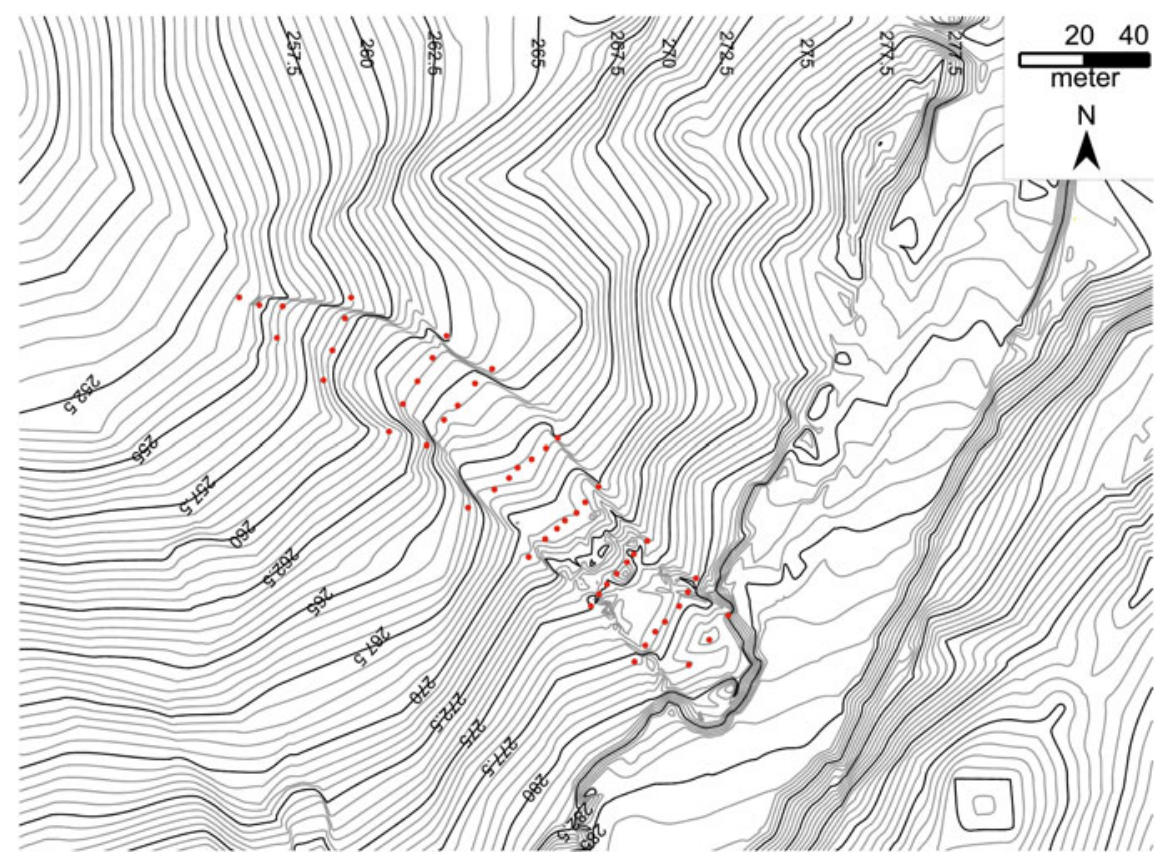

Fig. 4 Arrangement diagram of GPS monitoring piles displacement graph of the first row gauge piles
Fig. 5 The sliding

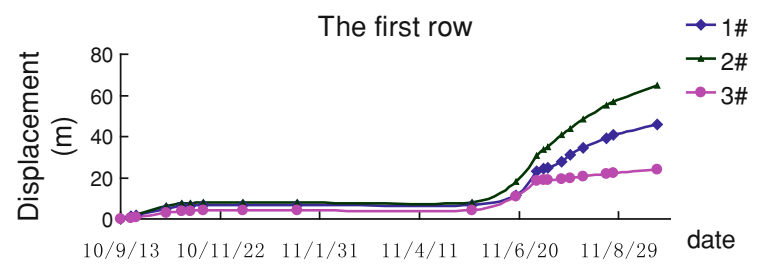

Fig. 6 The sliding displacement graph of the second row gauge piles

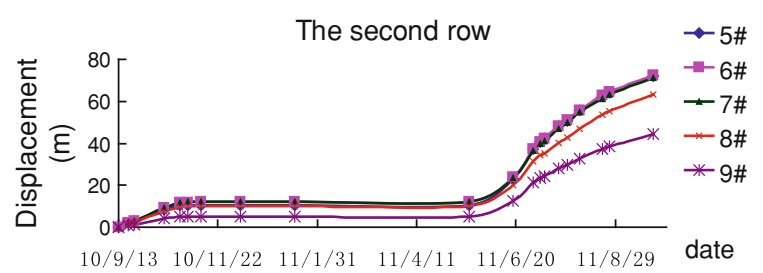

gauge piles sliding displacement in the central location of landslide are obviously bigger than gauge piles of sliding displacement near edge position.

From the gauge pile slip displacement curve (Fig. 7) in the central location of landslide, we can see that, from September 13, 2010 to September 25, 2011, during the 377 days, the gauge pile slip displacement from the first row to the seventh row respectively are $65.01 \mathrm{~m}, 71.31 \mathrm{~m}, 64.20 \mathrm{~m}, 54.23 \mathrm{~m}, 46.37 \mathrm{~m}$, and $39.43 \mathrm{~m}$. 


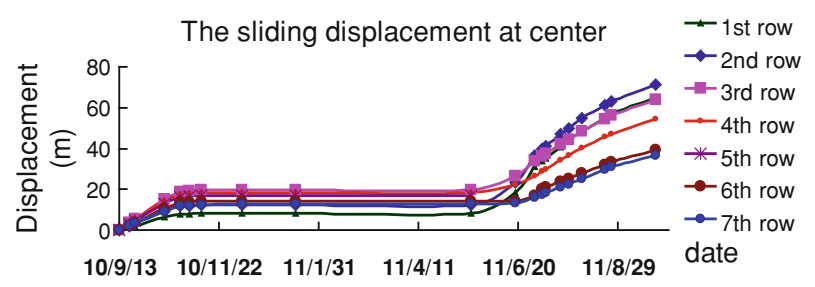

Fig. 7 The gauge pile slip displacement curve in the central location of landslide

It shows that, sliding displacements of different positions are large different during the same time. Sliding displacement of the middle and upper sector is the farthest, sliding displacement of the lower sector is the smallest.

\section{Resistivity of Landslide Based on High Density Resistivity Method}

\subsection{The Arrangement of High Density Resistivity Measuring Line}

During application of high density resistivity method in $\mathrm{K} 178+530$ section, we use 2DRES 2D high-density resistivity method inversion software to inverse least square method, inversion of the program we use is based on least square method which based on quasi-Newton algorithms for Nonlinear optimization, and module width is set to one-second unit electrode spacing to improve monitoring precision. To ensure depth and accuracy, the unit electrode spacing is $3.0 \mathrm{~m}$ in the test, sounding almost $30 \mathrm{~m}$.

Figure 8 shows the high density resistivity measuring line at K178 +530 landslide sections along the landslide (vertical road direction). The measuring line was from median strip, respectively going through the landslide rear edge, drilling ZK2 and drilling ZK1 location and stretching into $177 \mathrm{~m}$ along landslide to where is $32 \mathrm{~m}$ distance from forefront of landslide, the distance of landslide back edge, drilling ZK2 and drilling ZK1 location from the first electrode respectively are $9 \mathrm{~m}$, and $42 \mathrm{~m}$, and $96 \mathrm{~m}$. The numbers of electrode arrangement: the numbers 1-60 are successively arranged from the median strip of road location to the leading edge of landslide. During the test, Wenner arrangement method was used. 


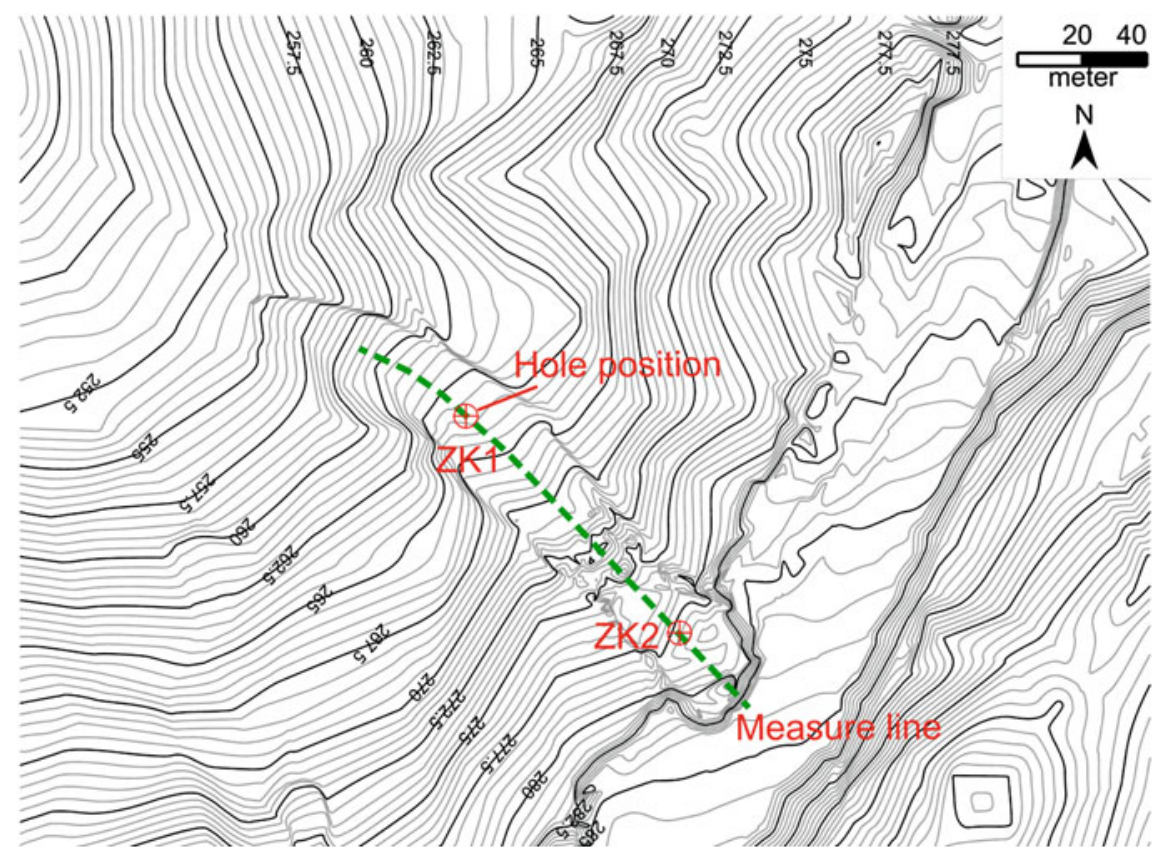

Fig. 8 The high density resistivity measuring line

\subsection{The Landslide Soil Resistivity Change Before and After the Landslide Forming}

We began investigation and study on K178 + 530 areas from May 2010, before July 22, 2010, K178 + 530 landslides had been in stable state. On July 22, 2010, two deformation monitoring pipes on the landslide body were sheared respectively in the depth of $4.2 \mathrm{~m}$ and $6.5 \mathrm{~m}$ under the ground, the sensor connection lines were also sheared, accordingly, we determined that the landslide soil began sliding. During the application of high density resistivity method in the process of investigation and study on $\mathrm{K} 178+530$ landslides, on June 1, 2010, and September 10, 2010, we did twice measure on the landslide, gaining the landslide soil resistivity change before and after the landslide forming.

As shown in Fig. 9 is the inversion images of landslide soil resistivity on June 1, 2010, when the landslide had not yet been formed and the landslide body had not yet started to slide. Through the inversion images of resistivity we could get: before the landslide body formed, landslide body's resistivity values was monotone decreasing with the depth increase, and had no jumping phenomenon of resistivity values.

As Shown in Fig. 10 is landslide soil resistivity inversion image on September 10,2010 . By the resistivity inversion image we can get: there is an obvious layered 


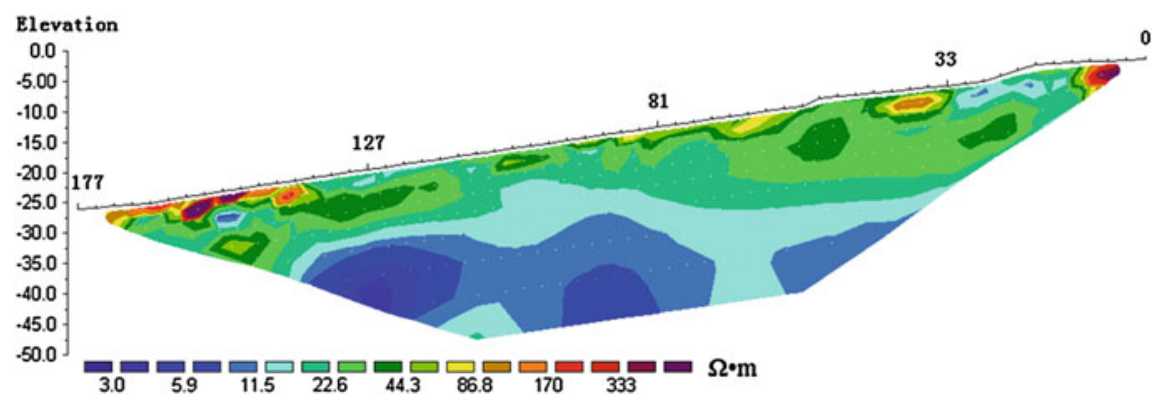

Fig. 9 The inversion images of landslide soil resistivity on June 1, 2010

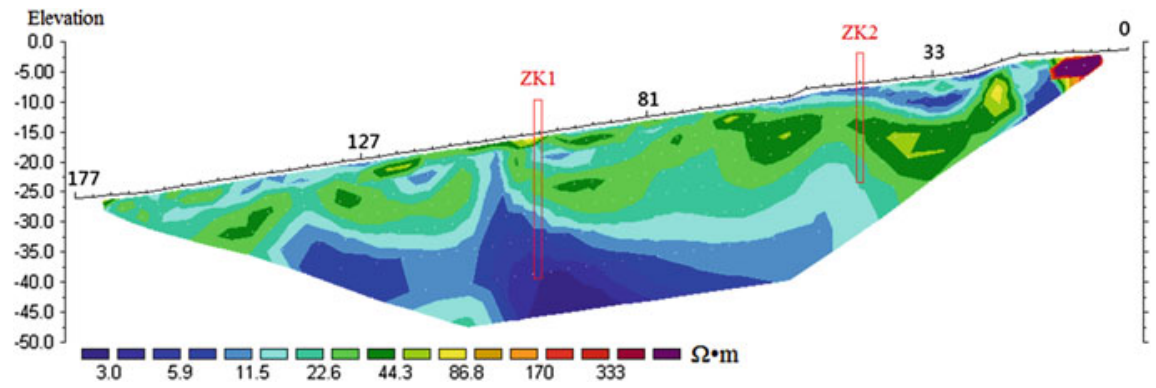

Fig. 10 The inversion images of landslide soil resistivity on September 10, 2010

of landslide soil resistivity and clear differences of sliding surface soil resistivity value after landslide formed.

The first electrode distance of $96 \mathrm{~m}$ (drilling 1 position), resistivity value as shown Figs. 10, 11. Depth 0-2.1 m is silty clay, which containing about $15 \%$ of the organic matter as grassroots ect., and resistivity value is $20-67 \Omega \cdot \mathrm{m}$; Depth 2.1-6.7 $\mathrm{m}$ is silty clay, which local have weathered sand sandwich, and resistivity value is $15-32 \Omega \cdot \mathrm{m}$; Depth $6.7-8.0 \mathrm{~m}$ is mudstone, and its structure is pieces, and resistivity value is $46-54 \Omega \cdot \mathrm{m}$; Depth $8.0-26 \mathrm{~m}$ is gray mudstone, where is close to ground water level or below ground water level in the underground, and resistivity value smaller is $10-35 \Omega \cdot \mathrm{m}$. In $0-2.1 \mathrm{~m}$ depth is silty clay that contains a lot of grassroots, water down the plant roots to infiltrate is easy; Below $6.7 \mathrm{~m}$ is mudstone, the permeability coefficient is small, water is difficult to infiltrate, forming water-resisting layer. Water is easy to gather in the top surface of mudstone layer, mudstone in water softening disintegration and easy to form the sliding surface. Due to the local weathered sand sandwich, the silty clay in 2.1-6.7 $\mathrm{m}$ depth can make water infiltrate easily.

The first electrode distance of $42 \mathrm{~m}$ (drilling 2 positions), resistivity value as shown Figs. 10, 12. In $0-4.5 \mathrm{~m}$ depth, resistivity value is $10-27 \Omega \cdot \mathrm{m}$, the surface layer road building abandon soil give priority to silty clay (Depth 0-3.8 m), resistivity value is $15-27 \Omega \cdot \mathrm{m}$, resistivity value of sand gravel (Depth $3.8-4.5 \mathrm{~m}$ ) is $10-22 \Omega \cdot \mathrm{m}$. Below $4.5 \mathrm{~m}$ is siltstone, particles smaller and seepage ability is 
Fig. 11 Resistivity curve of drilling 1 position

Fig. 12 Resistivity curve of drilling 2 position
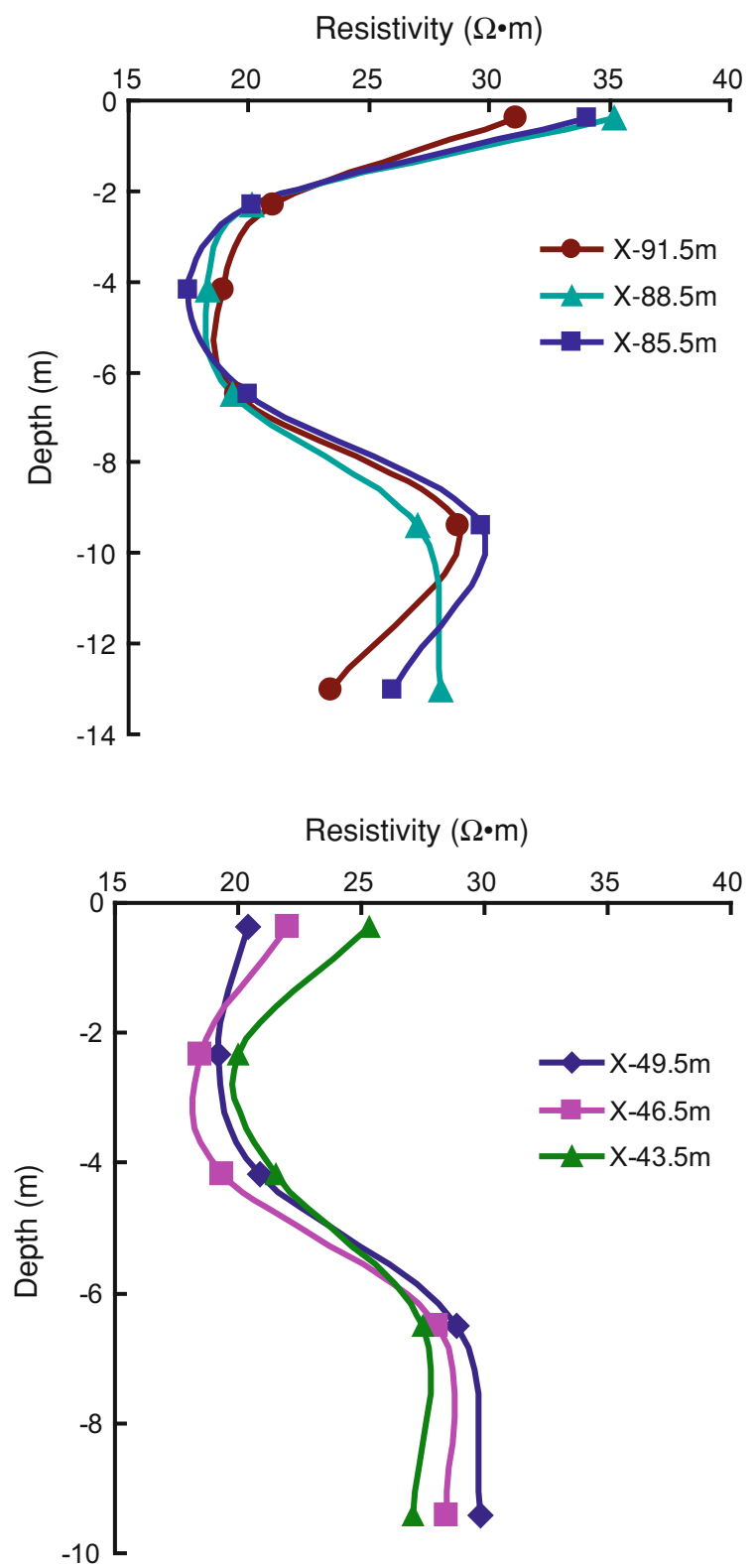

poor, forming water-resisting layer. The soil infiltration to $4.5 \mathrm{~m}$ depth location is easy to gather and form the sliding surface. In the $4.5 \mathrm{~m}$, the position of sand gravel and siltstone handover, the resistivity apparent stratification. Depth $0-4.5 \mathrm{~m}$, the soil is good permeability, water infiltrates easily; Depth $4.5-9.7 \mathrm{~m}$ is siltstone, and resistivity value is $25-54 \Omega \cdot \mathrm{m}$; Depth $9.7-14.6 \mathrm{~m}$ is sandstone, and resistivity value is $21-43 \Omega \cdot \mathrm{m}$. 


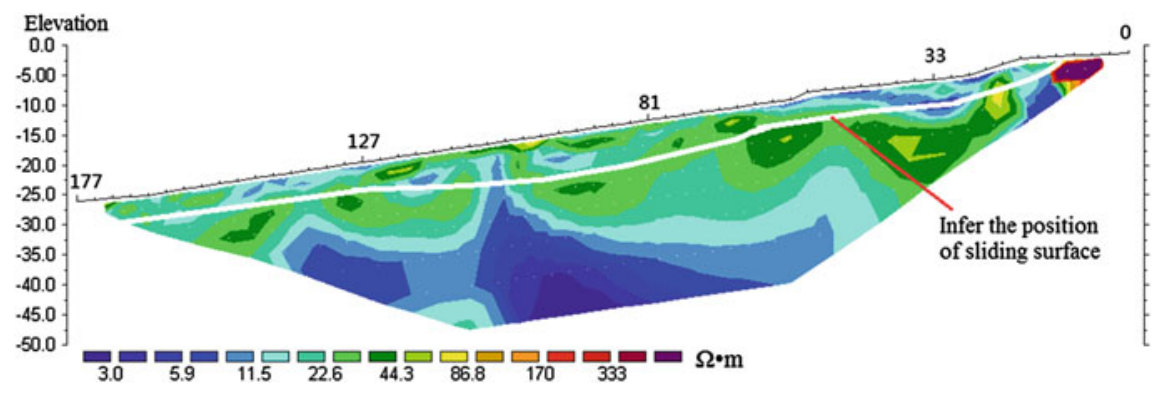

Fig. 13 Infer the position of sliding surface

The resistivity value at the slip surface location showed significant stratification and the resistivity values of its upper and lower show more obvious differences. According to the typical characteristic of the slip surface, we can infer the position of sliding surface, as shown Fig. 13.

\section{Conclusion}

(1) The slope failure belongs to superficial and translational movement on bedding planes in permafrost region. The soil within the sliding surface is silty clay, which is loose when dry, soft and plastic. The main triggering factor observed was freeze-thaw which has cycle have far-reaching consequences for the landslide, exhibiting intermittent slide and bench slope. There are Drumlin fields on the landslide slope. Snowmelt water, rainwater and fissure water provide groundwater source for the landslide. Tympanites cracks on the slope contribute to atmospheric precipitation pool in the landslide and permeate into the landslide. High permeability of landslide soil mass provides passage for water infiltration; mudstone and sandstone with low permeability form aquifuge while silty clay above the aquifuge is influenced by infiltration water to reach saturation, forming rupture surface.

(2) Different locations on the landslide have large different sliding displacements during the whole monitoring period. The displacement near the main scarp is largest, 50-72.56 m; at the middle of the landslide is $36.69-46.37 \mathrm{~m}$, near landslide toe is $8.25-30 \mathrm{~m}$. On the landslide exists bedding son-landslide, the distance between son-landslide flank and mother-landslide flank is $1.5-4 \mathrm{~m}$, within the same cross section of landslide, the sliding displacement of center is largest, the sliding displacement near landslide flank is smallest.

(3) Sliding velocity of the landslide is large different in different seasons. From mid-November to late May of the following year, Rainfall was very small, the surface layer of ground was frozen, Landslide was at rest all the while; In late May of the following year, Due to the seasonal frozen ground melts and 
snow cover melting and infiltrating, Landslide began slipping once again, the sliding velocity of landslide was fastest in this period (from late May to midJune), sliding velocity of rear edge was $0.89 \mathrm{~m} / \mathrm{d}$, sliding velocity of middle landslide was $0.37 \mathrm{~m} / \mathrm{d}$, and sliding velocity near toe was $0.16 \mathrm{~m} / \mathrm{d}$; Sliding velocity began decreasing in late June, sliding velocity of rear edge was $0.51 \mathrm{~m} / \mathrm{d}$, sliding velocity of middle landslide was $0.30 \mathrm{~m} / \mathrm{d}$, and sliding velocity near toe was $0.11 \mathrm{~m} / \mathrm{d}$; After mid-October, sliding velocity of the landslide was slower, the average was $0.08 \mathrm{~m} / \mathrm{d}$.

(4) Using the high-density resistivity method to survey the landslide and its surroundings, and to accurately detect the landslide resistivity value at different locations, according to characteristic of resistivity value, and combined with drilling results, to determine the position of sliding surface: at rear edge, the position of sliding surface was at the depth of $3.2 \mathrm{~m}$ apart from the ground; at $30 \mathrm{~m}$ apart from rear edge, sliding surface was at the depth of $4.5 \mathrm{~m}$; at the middle landslide, sliding surface was at the depth of $6.5 \mathrm{~m}$; near the landslide toe, sliding surface was at the depth of $4 \mathrm{~m}$, at toe position, sliding surface was at the depth of $2.5 \mathrm{~m}$. Within the same cross section of landslide, sliding surface of center is deepest; sliding surface near landslide flank is shallowest.

(5) At the position of the sliding surface, the resistivity is obviously low, about $7-20 \Omega \mathrm{m}$; the resistivity at the position of landslide flank shows a sudden change, obviously large. Resistivity value of soil on the landslide is lower than resistivity value of soil at the same depth of outside landslide.

Acknowledgments This work was financially supported by Heilongjiang Communications Department project and subtopic of the western communication science and technology project "Study on Subgrade Stability Controlling Technology of Expressway Expansion Project Permafrost Melt and Landslides Sections".

\section{References}

Feng SR, Feng DX, Ge XR et al (1999) 3D limit equilibrium method for slope stability and its application. Chin J Geotech Eng 21(6):657-661

GB50021-2001 (2002) Geotechnical engineering investigation specification. China Architecture \& Building Press, Beijing

He YX (1991) Application of D.C electric sounding for the permafrost exploration along Xinjiang-Xizang highway. J Glaciol Geocryol

Kong FL, Chen C, Sun GJ (2008) Application of multi-electrodes electrical method to landslide investigation in Qingjiang Shuibuya reservoir. Chin J Eng Geophys 5(2):201-204

Liu LH, Zhu DY, Liu DF (2007) Discussion on multiple solutions of safety factor of a slope. Rock Soil Mech 28(8):1661-1664

Shan W, Liu HJ, Yang L et al. (2008) Study of regularity of variation of water content in shallow layer of soil road cutting slopes in seasonally frozen-ground region. Rock Soil Mech 29(sup.):335-340

Zhu Y, Rao Z, Wu B (2008) Organic and gas geochemistry of gas hydrate-bearing sediments from mallik 5L-38 production research well, Mackenzie Delta Canada. Geol surv Can Bull 68(2):311-319 